\title{
THE EFFECTS OF NAVIGATION AND TYPES OF NEIGHBORHOODS ON TIMELY FOLLOW-UP OF ABNORMAL MAMMOGRAM AMONG BLACK WOMEN
}

Sage Kim, Yamile Molina, Anne Elizabeth Glassgow, Jenny Guadamuz, Elizabeth Calhoun

\begin{abstract}
:
Background: Despite the availability of relatively simple and inexpensive screening tools, minority women are more often diagnosed at a late stage of breast cancer, in part due to delays in follow-up of abnormal screening result. One of the key factors for timely follow-up of abnormal mammogram may be neighborhood characteristics. Patient Navigation (PN) programs aim to diminish barriers, but its differential effects by neighborhood have not been fully examined. The current study examines the effect of types of neighborhoods on time to follow-up of abnormal mammogram, and the differential effects of PN by neighborhood characteristics.
\end{abstract}

Methods: We examined data from a total of 1,696 randomized patients from a randomized controlled trial, "the Patient Navigation in Medically Underserved Areas" study that explored the effect of navigation on breast health outcomes. We categorized participants' neighborhoods into three categories and compared the effect of navigation between these neighborhood types.

Results: Navigated women in mixed race neighborhoods had a shorter time to follow-up compared with non-navigated women in the neighborhoods. Black women living in mixed neighborhoods had a significant longer time to follow-up of abnormal mammogram, compared with black women living in middle class black neighborhoods.

Conclusion: Patient navigation interventions improve timely follow-up of abnormal mammogram. Patient navigation may be particularly beneficial for minority women who reside in racially heterogeneous neighborhoods which may be less likely to have access to affordable health clinics and social services. Health policies concerning breast cancer early detection for minority women need to pay further attention to those who might potentially be excluded from health services due to the characteristics of neighborhoods. Socioeconomic conditions of neighborhood may affect individual health through multiple interlinked mechanisms. Neighborhood characteristics, such as poverty, segregation, access to resources, and social cohesion, cannot be fully understood with simplistic measures of neighborhood disadvantage.

Keywords: breast cancer; health disparity; follow-up; neighborhood effects 


\section{BACKGROUND}

Reducing the black-white disparity in breast cancer-related mortality is a public health priority. Despite having lower incidence rates [1], black women have a higher mortality rate (30.8 per 100,000) compared with white women (22.1 per 100,000) [2]; black women also have a lower five year survival rate compared with their white counterparts [1, 3]. Although the causes of disparities are multifactorial, one modifiable determinant is stage at diagnosis [4]. Screening mammography has been shown to identify breast cancer at an early stage and is associated with a $44 \%$ reduction in risk of late-stage disease $[5,6]$. Nonetheless, despite the availability of relatively simple and inexpensive screening tools, racial/ethnic minority women are more often diagnosed at a late stage of breast cancer and, subsequently, face higher mortality rates relative to white counterparts [1, 5, 7-15]. In particular, late stage diagnosis in minority women has been attributed in part to delays in diagnostic testing after an abnormal screening result relative to their white counterparts $[5,16]$. Timely follow-up of abnormal test results can help early detection of abnormal changes, which can significantly reduce the cancer mortality rates, but studies have documented that racial/ethnic minority women were less like to follow-up abnormal mammogram [17-20]. Despite the availability of relatively simple and inexpensive screening tools, racial/ethnic minority women are more often diagnosed at a late stage of breast cancer and, subsequently, face higher mortality rates relative to white counterparts [1, 5, 7-15]. Improving early detection practices among this population and specifically time to diagnostic resolution is thus an effective strategy to address racial disparities in breast cancer related deaths among black women.

\subsection{Predictors to timely follow-up: The role of neighborhoods}

A myriad of factors including psycho-social, economic, cultural, and systems level barriers may affect timely follow-up in diagnostic testing [21-23]. Notably, the majority of work has focused on patient-level factors. For example, under or uninsured women were less likely to follow-up abnormal test results [24]. Women with less education and/or being poor were less likely to complete followup of abnormal mammogram [22, 24, 25]. Younger women were also less likely to follow-up abnormal findings than older women [25].

Studies have documented that neighborhood characteristics affect a myriad of health outcomes [26-31], including breast health. Dailey and colleagues explored neighborhood level predictors for breast cancer screening outcomes [29, 32-40], and a few other studies examined contextual level factors affecting breast cancer screening behavior $[33,41-45]$. These studies indicate that neighborhood level poverty, racial residential segregation, and/or overall structural disadvantage were associated with poor breast cancer screening [29, 4650].

The negative effects of racial residential segregation on cancer screening, care, and mortality have been well documented [51-53]. However, studies have also documented that minorities living in areas with a higher proportion of their own racial/ethnic group report better health [54-58]. These studies argue that, once controlling for 
socioeconomic disadvantages due to racial segregation, a high "ethnic density" provides social cohesion and sense of belonging which have protective and buffering effects against discrimination and social exclusion that minorities may experience when they live in predominantly white areas $[54,57]$. Black women living in more racially heterogeneous neighborhoods may experience more social isolation and have less social support, which may affect their adherence to recommended breast cancer care [59, 60]. Such mechanisms may underlie other work that has indicated a protective effect on breast cancer mortality from black women living in racially homogeneous neighborhoods [61]. Very little is known about neighborhood characteristics and follow-up of abnormal mammogram results. There is a need to evaluate both the influences of neighborhood disadvantage and ethnic density on this outcome. Women living in racially segregated and poor neighborhoods may lack access to quality health care facilities, which may affect timely follow-up of abnormal mammogram results. Conversely, women living in racially heterogeneous neighborhoods may experience a greater level of psychosocial barriers, which may influence their adherence and timely follow-up.

\subsection{Patient navigation, neighborhoods, and timely follow-up}

Interventions that address barriers to timely follow-up should address the myriad of psychosocial, economic, and contextual determinants influencing early breast cancer detection practices [62-65]. Patient Navigation (PN) represents such an effective, multi-stage approach for both routine screening and timely follow-up of abnormal screening results [19, 66-69] through reducing psychosocial, economic, and contextual barriers [65, 70-72]. Implemented in various settings, including safety-net clinics, urban hospitals and community health centers, and academic medical facilities $[67,70,72-74]$, the majority of PN breast cancer-related care programs have been implemented to support women who are living in underserved areas [19, 65, 75-78]. The majority of work to date has largely focused on how PN addresses with patientlevel barriers; little is known about how PN may buffer or diminish the influence of contextual barriers on routine screening and timely follow-up, although PN programs have been implemented in various disadvantaged and underserved geographic regions and neighborhood effects have been studied in these populations [46].

Understanding if and how PN may mitigate the influence of neighborhood effects on breast cancer-related outcomes however needs to be examined. Given the goals and objectives of PN are to diminish barriers, such as those experienced by living in disadvantaged neighborhoods, it may be that neighborhood differences may be attenuated or eliminated among navigated women, in contrast to women who receive standard care. Nonetheless, the four studies that have incorporated neighborhood-level factors have often included them in final models as potential confounders or other predictors of interest, but have not formally examined interactive effects or examined the relationship of these factors on outcomes across different study arms within PN programs [46, 65, $68,77]$.

The current study addresses this gap in the literature by examining the 
effect of types of neighborhoods on time to follow-up of abnormal mammogram, and the differential effects of $\mathrm{PN}$ by neighborhood characteristics concerning time to follow-up of abnormal mammogram result. In particular, we examine the outcome differences among black women living in poor black neighborhoods, middle class black neighborhoods, and middle class mixed race neighborhoods to tease out the effects of neighborhood poverty and racial/ethnic composition, while paying attention to potential demographic, social, and economic barriers at the individual level.

\section{METHODS}

\subsection{Procedures}

We examined data collected between 2010 and 2011 as part of the Patient Navigation in Medically Underserved Areas study, a randomized controlled trial conducted to explore the effect of navigation on breast health outcomes. The study was approved by the University of Illinois at Chicago Institutional Review Board. The study recruited female patients, age 18 or older, who were not pregnant with an initial referral from a primary care provider for a screening mammography or for a diagnostic mammography based on an abnormal clinical breast exam from community hospitals situated in medically underserved areas. Patients eligible for the study who had screening or diagnostic mammography appointments were randomized into either the navigation group or the control group. All other patients not randomized into either the navigation or active control group were considered the passive control group. Eligible patients were recruited by phone or in-person from the hospital scheduled mammogram appointment list. Patients were contacted about their upcoming mammogram, and asked if they were interested in participating in the study. Patients who agreed to participate in the study completed a series of baseline questionnaires with a navigator via telephone or in-person interview. A total of 1,696 randomized patients completed baseline questionnaires. In addition to questionnaire data, medical records data were retrieved from electronic medical record systems for both the navigated and the control group.

The patient navigation intervention was developed using a lay patient navigator model. Navigators were lay health workers who live in areas from which study population resides and share sociodemographic characteristics with the population. Patients randomized to the intervention group received navigation by a trained navigator. Two days before patient's imaging appointment, the navigator called the patient and used a "teach back" method to ensure the patient understood the instructions for the mammography preparation, answered any questions, assessed any potential barriers to attending the appointment, and problem solved to eliminate these potential barriers. On the day preceding the appointment, the study participants received a reminder call about the appointment and re-assessed any potential barriers to compliance. The navigator then met with the patient at the appointment to assess if the patient had any questions, provided education and information, and discussed how the results of the exam would be communicated to the patient.

The navigator worked with the hospital clinical staff to ensure results were delivered to the patient and that the patient understood the results and the 
recommended follow-up (annual rescreening, additional diagnostic testing, or treatment initiation). Patients who continued with diagnostic testing or treatment completed an additional questionnaire designed to explore what clinical services were offered, what the patient understood about these services, what services were accepted by the patients and reasons for their decision. Patients randomized to the control group received care as usual at each hospital and did not receive any navigation services. Patients randomized to the control group were followed up with the study questionnaires. No navigation services were offered and no assistance with appointments, barriers or screening results offered. We compared women in the navigated and the control groups for this analysis.

\subsection{Measures}

Intervention variable was a dichotomous measure which categorized study participants into navigated or control groups. Time to follow-up of abnormal mammogram was calculated using the initial mammography appointment date and the date of a follow-up diagnostic resolution for women who received an abnormal result. In this analysis, we included mammogram resulted in BIRADS 0, 4, and 5. The Breast Imaging Reporting and Data System (BI-RADS) is a system that categorized mammogram results [79]. BI-RADS 0 means a possible abnormality may not be clearly seen or defined and more tests are needed. BIRADS 4 indicates suspicious abnormality and it requires a biopsy. BI-RADS 5 indicates highly suggestive of malignancy and biopsy is strongly recommended for a follow-up. BI-RADS 0, 4, and 5 results are recommended to have a follow-up test done within 180 days. BI-RADS 1 means negative, BI-RADS 2 indicates benign finding, and BI-RADS 3 suggests high chance of benign but a repeat imaging is needed for confirmation.

Individual level socio-demographic characteristics included age, income, education level, employment status, marital status, and household size. For the analysis we dichotomized education level into less than high school education and high school and more. We used household income and household size to determine whether they live below federal poverty level. For example, in 2010, a household size of four with household income less than $\$ 22,000$, and a household of eight with income below $\$ 37,000$ were considered to be below poverty level [80]. Marital status was dichotomized into married and other. Employment status was dichotomized into full time employed and other. Insurance status included private, public insurance, and uninsured. Because the majority of study participants had either private or public insurance (over 99\%), we compared private insurance with all others for this study. In addition, we calculated distance from home to the hospital where participants received mammogram.

Table 1. Summary of three latent classes of neighborhoods

\begin{tabular}{lccc}
\hline Label & Poor black & Middle class black & $\begin{array}{c}\text { Middle class } \\
\text { mixed race }\end{array}$ \\
\hline Neighborhood Class & 1 & 2 & 3 \\
\hline Latent Class Prevalence & $24 \%$ & $61 \%$ & $16 \%$ \\
\hline
\end{tabular}




\begin{tabular}{lccc} 
Total N & 1,073 & 3,704 & 892 \\
\hline Characteristics & & & \\
\% black & 92.60 & 91.96 & 17.63 \\
\% white & 3.26 & 5.26 & 52.35 \\
\% Hispanic & 5.35 & 2.50 & 45.90 \\
HH median income & $\$ 26,301$ & $\$ 44,496$ & $\$ 45,875$ \\
\% owned home & 35.06 & 61.64 & 62.57 \\
\% poverty & 39.89 & 18.96 & 19.79 \\
\% unemployed & 24.16 & 16.13 & 11.62 \\
\% less than HS & 18.50 & 10.59 & 11.43 \\
\% female headed HH & 29.08 & 19.28 & 13.00 \\
\% owned home & 35.06 & 61.64 & 62.57 \\
\hline
\end{tabular}

To examine the effect of neighborhood characteristics on time to follow-up, we used census-tract level data, which has been suggested to operationalize neighborhoods and related characteristics better than zip codes $[26,40]$. We used the eight neighborhood measures to define type of neighborhood, including \% poverty, \% black, $\%$ white, $\%$ Hispanic, $\%$ female headed households, \% less than HS education, $\%$ unemployed, and median household income. Latent class analysis (LCA) was used to classify types of neighborhoods. This is an alternative to the commonly used concentrated disadvantage index, which is a concept that describes the degree of neighborhood economic and social disadvantages [81, 82] and is a continuous variable which implies a linear relationship between the score and neighborhood disadvantage and its negative effects. We argue that the relationships are not necessarily linear between neighborhoods and health outcomes. Qualitatively different types of neighborhoods exist that can be classified into distinct classes. The assumption of LCA is that the relationship among dichotomous indicators can be explained by categorical latent variables [83]. To determine the best model, we compared
LCA models up to four classes by examining AIC and BIC statistics for each model with different number of classes. The three-class model fit data best with AIC and BIC values of respectively 65.80 and164.69 relative to the four class model $(\mathrm{AIC}=69.53$; and $\mathrm{BIC}=203.31)$. These neighborhoods were identified as poor black (Class 1), middle class black (Class 2) and middle class mixed neighborhoods (Class 3). Table 1 summarizes characteristics of these three types of neighborhoods.

\subsection{Analysis}

First, we compared characteristics of navigated women and the control using descriptive statistics (Table 2). Second, we then conducted linear regression analysis to examine the effect of navigation on the length of time to follow-up of abnormal mammogram (Table 3). To fully examine potential interaction effects between neighborhood types and navigation status, we introduced interaction terms with navigation status and neighborhood class dummy variables (Model 2). We then ran regression models separately for the navigated and the controls (Model 3). Finally, we controlled for other factors that 
have been shown to affect the length of time to follow-up (Model 4), and examined the relationships by navigation status (Model 5).

\section{RESULTS}

Table 2 summarizes the sample characteristics. Navigated women were more likely to be older and unemployed than controls; on the other hand, navigated women were more likely to have private health insurance than the controls. In terms of neighborhood characteristics, navigated women were more likely, compared with the controls, to live father away from the hospital from which they received the mammogram. Although the majority of study participants were from predominantly black communities, navigated women were more likely to live in neighborhoods with a greater proportion of blacks. Overall, navigated women were more likely to live in middle class black neighborhoods and the controls were more likely to live in middle class mixed. In the subsequent analysis, we controlled for these differences between the navigated and controls, because these differences may influence for any main and interactive effects on the time to follow-up as confounders.

Table 3 summarizes the relationships between the time to followup, neighborhood type, and the navigation status. When examining main effects, although the length of time to follow-up of abnormal mammogram was longer for the control group, compared with the navigated group, the difference was not statistically significant. When including interaction terms, navigated women in mixed neighborhoods had a significantly shorter time to follow-up compared with non-navigated women in the neighborhoods (Model I). Black women living in mixed neighborhoods had a significant longer time to follow-up of abnormal mammogram, compared with black women living in middle class black neighborhoods. When we included individual sociodemographic factors in the model using all cases (Model III), the interaction effect of neighborhood and navigation disappeared.

Table 2. Sample characteristics

\begin{tabular}{lcccc}
\hline & Total & Navigated & Control & P \\
\hline $\mathrm{N}=1,608$ & 12.1 & 11.9 & 15.5 & $<.01$ \\
Age & 60 & 60 & 57 & $<.01$ \\
Poverty & 23.1 & 22.4 & 27.6 & n.s. \\
Income $<\$ 30,000$ & 40.6 & 39.9 & 45.4 & n.s. \\
Insurance & & & & $<.05$ \\
$\quad$ Private insurance & 73.5 & 74.0 & 70.2 & \\
$\quad$ Public insurance & 26.4 & 25.9 & 28.9 & \\
$\quad$ No insurance & 0.2 & 0.1 & 0.9 & \\
Marital status & & & & n.s. \\
$\quad$ Never married & 28.4 & 27.0 & 35.7 & \\
$\quad$ Married & 33.5 & 33.6 & 31.5 & \\
$\quad$ Divorced/Separated & 21.5 & 21.7 & 19.6 & \\
$\quad$ Widowed & 16.6 & 17.1 & 13.2 &
\end{tabular}

Education

n.s. 
$<$ High school

10.5

24.6

65.0

$>=$ College

Employment

Unemployed

Part time

Full time

Distance to Hospital

Neighborhood

$\%$ poverty
$\%$ white
$\%$ black
$\%$ unemployed
$\%$ less than $\mathrm{HS}$
$\%$ female headed $\mathrm{HH}$
Median $\mathrm{HH}$ income

23.0

11.0

82.5

16.9

12.2

20.4

$\$ 41,654$
10.0

24.6

65.4

13.2

24.3

62.4

$<.01$

50.7

6.7

38.5

8.5

22.8

10.8

82.9

16.9

12.1

20.2

$\$ 41,799$
37.8

6.9

48.5

7.4

$<.01$

24.4

n.s.

12.0

n.s.

$79.0<.05$

17.4 n.s.

$13.1 \quad$ n.s.

20.8 n.s.

$\$ 40,457$

n.s.
To further examine the differential effects of neighborhood type for the navigated and the controls, we ran separate regression analysis for those who were navigated and the controls. Model IV shows the regression results by navigation status. With regard to patient-level factors, navigated women who had a full time job had a shorter time to follow-up; on the other hand, full time employment was associated with a longer time to follow-up among the controls. In terms of neighborhood type, living in middle class mixed neighborhood was continued to be associated with a longer time to follow-up abnormal mammogram.

Table 3. Predicting time to follow-up by navigated status and neighborhood type

\begin{tabular}{lcccccc}
\hline & \multicolumn{7}{c}{ Model } & & & III & \\
\hline & I & II & & IV & \\
\hline Number of cases & All & Navigated & Control & All & Navigated & Control \\
\hline Navigated & 695 & 644 & 51 & 634 & 583 & 51 \\
Class 1 & 2.26 & - & - & 2.59 & - & - \\
Class 2 & 5.82 & -1.91 & 5.82 & 6.37 & -2.92 & 5.00 \\
Class 3 & - & - & - & - & - & - \\
Navigated*Class 1 & -7.74 & - & $-8.88^{*}$ & $26.09 *$ & 3.47 & $26.19 *$ \\
Navigated*Class 3 & $-23.38^{*}$ & - & - & -9.29 & - & - \\
Age & - & - & - & -0.08 & -0.03 & -0.55 \\
Married & - & - & - & -0.28 & -0.36 & 6.57 \\
$<$ HS edu & - & - & - & -1.53 & 0.89 & -13.95 \\
Private insurance & - & - & - & -1.64 & -0.17 & -16.51 \\
Full time employed & - & - & - & $-6.51 *$ & $-6.34 *$ & -7.81 \\
R2 & 0.0140 & 0.0033 & 0.1101 & 0.0272 & 0.0165 & 0.2689 \\
\hline
\end{tabular}




\section{DISCUSSION}

Overall, black women living in racially heterogeneous middle class neighborhoods seem to have a longer time to follow up after an abnormal mammogram compared with black women living in predominantly black middle class neighborhoods. This finding is interesting because it is counterintuitive at first glance, considering well established literature concerning the problem of racial residential segregation. The associations and interactions between neighborhood level disadvantage, poverty, racial residential segregation/homogeneity, and health outcomes may be far more complex due to the multiple mechanisms through which poverty, racial segregation and homogeneity may operate.

Currently, only a few studies have examined the neighborhood effects on follow-up of abnormal mammogram [17, 84]. Some studies examined delayed diagnosis of breast cancer $[45,61,85]$, and the findings from these studies indicate that neighborhood disadvantage and racial segregation was associated with delayed diagnosis of breast cancer. From the racial segregation perspective, one might conclude that minority women living in racially mixed neighborhood may have improved outcomes relative to women living in segregated neighborhoods. On the other hand, many studies have documented that minorities living in predominantly minority areas tend to show better health status [55-58]. For example, Warner and Gomez (2010) found that living in a neighborhood with more black residents was associated with lower breast cancer specific and all-cause mortality among black breast cancer patients. Similarly, Russell and colleagues suggested that breast cancer mortality rates were higher in racially mixed tracts that were located in Copyright @ 2015, Knowledge Enterprises Incorporated. All rights reserved. highly segregated metropolitan areas [86]. These studies argue that minorities living in areas with a high "group density" benefit from the sense of belonging and social cohesion that may mitigate the negative effects of discrimination and social exclusion which may be a greater burden for minority living in more racially mixed neighborhoods. Perhaps because these studies hypothesize psychosocial pathways through which racial composition/density may influence individual health outcomes, frequently these studies examine mental health outcomes.

Nonetheless, the main argument of these studies is that neighborhood characteristics affect individual health conditions not only through material conditions, but also through interactional social context $[57,58]$.

Our findings seem to support the buffering effects of group density argument on health. Our study is innovative, in that we were able to separate poor black neighborhoods from middle class black neighborhoods, which allowed us to compare middle class black neighborhoods with middle class mixed neighborhoods. Previous studies have not been able to tease out the effects of racial density from economic disadvantage, in part because highly segregated black neighborhoods are disproportionately more likely to be also economically deprived [87-90]. Our study provided a closer look at the effect of neighborhood racial composition separate from the level of economic deprivation. Our study finding indicates that although there was no difference between middle class black and poor black neighborhoods, but there was a significant difference between middle class black and middle class mixed neighborhoods. This finding suggests that area level racial composition may play a 
more significant role regarding timely follow-up of abnormal test results among black women. Although our data did not allow us to directly examine the level of social cohesion, we speculate that black women living in racially mixed neighborhoods in our study may experience a great degree of social isolation, while black women living in predominantly black neighborhoods benefit from a level of social cohesion and support which may be resulted from a high level of racial homogeneity [55-58].

Another potential explanation for the poorer follow-up of abnormal mammogram among black women living in middle mixed neighborhoods compared predominantly black neighborhoods may have to do with health policy associated with resource allocation. For example, by definition, federally qualified health centers are strategically located in underserved areas, which are often minority communities [91]. Consequently, poor women living outside of these neighborhoods may have more difficulty accessing healthcare. Indeed, our additional descriptive comparison between the three types of neighborhoods showed that the average travel time to the closest clinic was significantly longer for women living in middle class mixed neighborhoods compared with the time for women in middle class black neighborhoods (3.8 and 2.9, respectively). Although this is a topic beyond the primary aims of the current study, further research examining the relationship between neighborhood types and access to care among minority women may be beneficial.

Previous studies have documented that PN programs improved breast cancer screening and detection outcomes among minority women living in urban poverty areas [19, 46, 65, 77]. Our findings seem Copyright @ 2015, Knowledge Enterprises Incorporated. All rights reserved. to confirm the effectiveness of PN programs on timely breast cancer followup and early detection and indicate that navigation mitigates negative effects of socioeconomic conditions on timely follow-up. Examining the regression relationships for the navigated women and the controls, our findings showed that the effect of neighborhood type was no longer significant for the navigated women.

There are several limitations to the study. First, this was a secondary analysis of a pragmatic trial with a randomization scheme that was set to disproportionately designate women to receive navigation services. As such, there were limited number of controls for our analysis, which may have influenced our findings. Indeed, the navigated and the control groups differ in several sociodemographic characteristics, including age, poverty, employment status, and distance to the hospital. We controlled for these variables in our analysis, however, the problem with the difference in the size of the groups could not be adjusted. The other limitation of our analysis is that because of the high level of missing responses to the income question, we were not able to use direct measure of individual level poverty. Instead, we used education, insurance status, and employment to compare women's economic condition. These variables are reasonable proxy for income/poverty, but this analysis was not able to draw direct comparisons between the effects of neighborhood level and individual level poverty on follow-up of abnormal mammogram. Next, the current study focused on black women, for whom there are unique and striking disparities in breast cancer. Nonetheless, other ethnic/racial minorities with poor cancer outcomes, such as Hispanic women, need further research, and studies such as ours may help examine how neighborhood 
characteristics affect health outcomes among these populations.

Despite these limitations, however, this study offered unique contributions to better understanding the effects of patient navigation and neighborhood characteristics on follow-up of abnormal mammogram among black women. Our findings indicate that patient navigation interventions improve timely follow-up of abnormal mammogram which is a key element to early detection of breast cancer. Patient navigation may be particularly beneficial for minority women who reside in relatively well-to-do and racially heterogeneous neighborhoods which may be less likely to have access to affordable health clinics and other social services. Publicly funded health programs, including Medically Underserved Area (MUA) designation, federally qualified health centers (FQHCs), and National Breast and Cervical Cancer Early Detection Program (NBCCED), are targeted to improve access to care for individuals living in underserved, often racially segregated areas. However, health policies concerning breast cancer early detection for minority women need to pay further attention to those who might potentially be excluded from existing health and social services due to the characteristics of neighborhoods where they live.

Socioeconomic conditions of neighborhood may affect individual health through multiple interlinked mechanisms. Neighborhood characteristics, such as poverty, segregation, access to resources, and social cohesion, cannot be fully understood with simplistic measures of neighborhood disadvantage. Our study findings contribute to conceptualizing nonlinear nuanced neighborhood effects on health. 


\section{REFERENCES}

1. National Cancer Institute. SEER Cancer Statistics Review, 1975-2007. Bethesda, MD: National Cancer Institute; 2010.

2. Surveillance epidemiology and end results (SEER). SEER stat fact sheets: breast; 2013. National Cancer Institute, Bethesda, MD: 2013. Accessed on: Available at: http://seer.cancer.gov/statfacts/html/breast. html.

3. Illinois Department of Public Health. Cancer Mortality by Race, Illinois, 1986-2006; 2009.

4. Gerend MA, Pai M. Social Determinants of Black-White Disparities in Breast Cancer Mortality: A Review. Cancer Epidemiology, Biomarkers \& Prevention. 2008;17(11):2913-2923.

5. Malin Fair A, Wujckik D, Lin JMS, Zheng W, Egan K, Grau A, et al. Psychosocial determinants of mammography follow-up after receipt of abnormal mammography results in medically underserved women. Journal of Health Care for the Poor and Underserved. 2010;21((1 Suppl)):71-94.

6. Buseman S, Mouchawar J, Calonge $\mathrm{N}$, Byer T. Mammography screening matters for young women with breast carcinoma: evidence of downstaging among 42-49-year-old women with a history of previous mammography screening. Cancer. 2003;97(2):352-358.

7. Roetzheim RG, Pal N, Tennant C, Voti L, Ayanian JZ, Schwabe A, et al. Effects of health insurance and race on early detection of cancer. Journal of the National Cancer Institute. 1999;91(16):1409-1415.

8. Mandelblatt J, Howard A, Kemer J, Zauber A, Bumetu W. Determinants of late stage diagnosis of breast cancer and cervical cancer: the impact of age, race, social class, and hospital type. American Journal of Public Health. 1991;81(5):646649.

9. Mundt AJ, Connell PP, Campbell T, Hwang JH, Rotmensch J, Waggoner S. Race and clinical outcomes in patients with carcinoma of the uterine cervix treated with radiation therapy. Gynecologic Oncology. 1998;71(2):151158.

10. Grisby P, Hall-Daniels L, Baker S, Perez C. Comparison of clinical outcomes in black and white women treated with radiotherapy for cervical carcinoma. Gynecol Oncol. 2000;79:357-361.

11. Wang F, McLafferty S, Escamilla V, Luo L. Late-Stage Breast Cancer Diagnosis and Health Care Access in Illinois. Prof Geogr. 2008;60(1):54-69.

12. Eley JW, Hill HA, Chen VW, Austin DF, Wesley MN, Muss HB, et al. Racial differences in survival from breast cancer. Results of the National Cancer Institute Black/White Cancer Survival Study. JAMA. 1994;272(12):947-54.

13. Cross CK, Harris J, Recht A. Race, socioeconomic status, and breast carcinoma in the U.S: what have we learned from clinical studies. Cancer. 2002;95(9):1988-99.

14. American Cancer Society. Cancer Facts \& Figures 2009. Atlanta, GA: American Cancer Society; 2009.

15. Albano J, Ward E, Jemal A, Anderson R, Cokkinides V, Murray T, et al. Cancer Mortality in the United States by Education Level and Race. Journal of the National Cancer Institute. 2007;99(18):1384-1394.

16. Smith-Bindman R, Miglioretti DL, Lurie $\mathrm{N}$, al. e. Does utilization of screening mammography explain racial and ethnic differences in breast cancer? 
Ann Intern Med. 2006;144(8):541-553.

17. Press $\mathrm{R}$, Carrasquillo $\mathrm{O}$, Sciacca RR, Giardina E-GV. Racial/Ethnic Disparities in Time to Follow-Up after an Abnormal Mammogram. Journal of Women's Health. 2008;17(6):923-930.

18. Adams SA, Smith ER, Hardin J, Das IP, Fulton J, Hebert JR. Racial Differences in Follow-up of Abnormal Mammography Findings Among Economically Disadvantaged Women. Cancer. 2009;115(24):5788-5797.

19. Markossian TW, Darnell JS, Calhoun EA. Follow-Up and Timeliness After an Abnormal Cancer Screening Among Underserved, Urban Women in a Patient Navigation Program. Cancer Epidemiology, Biomarkers \& Prevention. 2012;21(10):1691-1699.

20. Gorin S, Heck J, Cheng B, Smith $\mathrm{S}$. Delays in breast cancer diagnosis and treatment by racial/ethnic group. Arch Intern Med. 2006;166(20):2244-2252.

21. Rojas M, Mandelblatt J, Cagney K, Kerner J, Freeman H. Barriers to followup of abnormal screening mammograms among low-income minority women. Cancer Control Center of Harlem. Ethn Health. 1996;1(3):221-228.

22. McCarthy B, Yood M, Janz N, Boohaker E, Ward R, Johnson C. Evaluation of factors potentially associated with inadequate follow-up of mammographic abnormalities. Cancer. 1996;77:2070-2076.

23. Williams D, Tortu S, Thomson J. Factors associated with delays to diagnosis and treatment of breast cancer in women in a Louisiana urban safety net hospital. Women Health. 2010;50(8):705-718.

24. Strzelczyk J, Dignan M. Disparities in adherence to recommended follow-up on screening mammography: interaction of sociodemographic factors. Ethn Dis.
2002;12:77-86.

25. Yabroff K, Breen N, Vernon S, Meissner H, Freedman A, Ballard-Barbash R. What Factors Are Associated with Diagnostic Follow-Up after Abnormal Mammograms? Findings from a U.S. National Survey. Cancer Epidemiol Biomarkers Prev. 2004;13(5):723-732.

26. Krieger N, Chen JT, Waterman PD, Soobader MJ, Subramanian SV, R. C. Geocoding and monitoring of US socioeconomic inequalities in mortality and cancer incidence: does the choice of area-based measure and geographic level matter?: the public health disparities geocoding project. Am J Epidemiol. 2002;156:471-482.

27. Roux AVD, Mair C. Neighborhoods and health. Annals of the New York Acadamy of Sciences. 2010;1186:125-145.

28. Lochner K, Kawachi I, Brennan R, Buka S. Social capital and neighborhood mortality rates in Chicago. Social Science \& Medicine. 2003;56:1797-1805.

29. Kawachi I, Berkman LF. Neighborhoods and health. Oxford ; New York: Oxford University Press; 2003.

30. Kirby J. Poor people, poor places, and access to health care in the US. Soc Forces. 2008;87(1):325-355.

31. Schultz W. Racial and spatial relations as fundamental determinants of health in Detroit. Milbank. 2002;80(4):5456.

32. Dailey AB, Kasl SV, Holford TR, Calvocoressi L, Jones BA. NeighborhoodLevel Socioeconomic Predictors of Nonadherence to Mammography Screening Guidelines. Cancer Epidemiology Biomarkers and Prevention. 2007;16(11):2293-2303.

33. Rosenberg L, Wise LA, Palmer JR, 
Horton NJ, Adams-Campbell LL. A Multilevel Study of Socioeconomic Predictors of Regular Mammography Use Among African-American Women. Cancer Epidemiology Biomarkers and Prevention. 2005;14(11):2628-2633.

34. Jones BA, Dailey A, Calvocoressi L, Reams K, Kasl SV, Lee C, et al. Inadequate Follow-up of Abnormal Screening Mammograms: Findings From the Race Differences in Screening Mammography Process Study (United States). Cancer Causes and Control. 2005;16:809-821.

35. Burack RC, Simon MS, Stano M, George J, Coombs J. Follow-Up Among Women with an Abnormal Mammogram in an HMO: Is It Timely, Complete, and Efficient? American Journal of Managed Care. 2000;6(10):1102-1113.

36. Caplan LS, May DS, Richardson LC. Time to diagnosis and treatment of breast cancer: results from the National Breast and Cervical Cancer Early Detection Program, 1991-1995. American Journal of Public Health. 2000;90(1).

37. Chang SW, Kerlikowske K, Nápoles-Springer AM, Posner SF, Sickles EA, Pérez-Stable EJ. Racial differences in timeliness of follow-up after abnormal screening mammography. Cancer. 1996;78(7):1398-1402.

38. McCarthy BD, Yood U, Boohaker EA, Ward RE, Rebner M, Johnson CC. Inadequate follow-up of abnormal mammograms. American Journal of Preventive Medicine. 1996;12(4):252-288.

39. Yabroff KR, Washington KS, Leader A, Neilson E, Mandelblatt JS. Is the Promise of Cancer-Screening Programs Being Compromised? Quality of Follow-Up Care after Abnormal Screening Results. Medical Care Research and Review. 2003;60(3):294-331.

40. Galster G. On the nature of the neighbourhood. Urban Studies.
2001;38(12):2111-2124.

41. Kothari A, Birch S. Individual and regional determinants of mammography uptake. Can J Public Health. 2004;95:290294.

42. Schootman M, Jeffe D, Baker E, Walker M. Effect of area poverty rate on cancer screening across US communities. J Epidemiol Community Health. 2006;60:202-207.

43. Litaker D, Tomolo A. Association of contextual factors and breast cancer screening: finding new targets to promote early detection. J Womens Health. 2007;16:36-45.

44. Phillips K, Kerlikowske K, Baker L, Chang S, Brown M. Factors associated with women's adherence to mammography screening guidelines. Health Serv Res. 1998;33:29-53.

45. Zenk S, Tarlov E, Sun J. Spatial equity in facilities providing low- or nofee screening mammography in Chicago neighborhoods. J Urban Health. 2006;83:195-210.

46. Plascak JJ, Llanos AA, Pennell ML, Weier RC, Paskett ED. Neighborhood and Geographic Factors Associated with Diagnostic Resolution After an Abnormal Breast or Cervical Cancer Screening Test Among Women Enrolled in a Patient Navigator Program. Cancer Epidemiology, Biomarkers \& Prevention. 2014;23.

47. Lopez RP, H. Patricia H. Obesity, physical activity, and the urban environment: public health research needs. Environmental Health: A Global Access Science Source. 2006;5:25-10.

48. Pastor Jr M, Sadd JL, MorelloFrosch R. Waiting to Inhale: The Demographics of Toxic Air Release Facilities in 21st-Century California. Social Science Quarterly (WileyBlackwell). 2004;85(2):420-440. 
49. Heinrich KM, Rebecca EL, Regan GR, Reese-Smith JY, Howard HH, Haddock CK, et al. How Does the Built Environment Relate to Body Mass Index and Obesity Prevalence Among Public Housing Residents? American Journal of Health Promotion. 2008;22(3):187-194.

50. Cohen L, Chávez V, Chehimi S. Prevention is primary: strategies for community well-being. San Francisco, CA: Jossey-Bass; 2010.

51. Jennifer S. Haas, Craig C. Earle, John E. Orav, Phyllis Brawarsky, Marie Keohane, Bridge A. Neville, et al. Racial Segregation and Disparities in Breast Cancer Care and Mortality. Cancer. 2008 113(8):2166-2172.

52. Dajun Dai. Black residential segregation, disparities in spatial access to health care facilities, and late-stage breast cancer diagnosis in metropolitan Detroit. Health Place. 2010;16(5):1038-1052.

53. Harper S LJ, Meersman SC, Breen N, Davis WW, Reichman MC,. Trends in area-socioeconomic and race-ethnic disparities in breast cancer incidence, stage at diagnosis, screening, mortality, and survival among women ages 50 years and over (1987-2005). Cancer Epidemiol Biomarkers Prev. 2009;18(1):121-131.

54. Laia Bécares, Richard Shaw, James Nazroo, Mai Stafford, Christo Albor, Karl Atkin, et al. Ethnic Density Effects on Physical Morbidity, Mortality, and Health Behaviors: A Systematic Review of the Literature. American Journal of Public Health. 2012;102(12):e33-e66.

55. J. Boydell JvO, K. McKenzie, J. Allardyce, R. Goel, R.G. McCreadie, R.M. Murray. Incidence of schizophrenia in ethnic minorities in London: Ecological study into interactions with environment. British Medical Journal. 2001;323(7325):1336-1338.

56. Cochrane R, Bal SS. Ethnic density is unrelated to incidence of schizophrenia. British Journal of Psychiatry. 1988;153:363-366.

57. Kate E. Pickett, Richard G. Wilkinson. People like us: ethnic group density effects on health. Ethnicity \& Health. 2008;13(4):321-334.

58. Laia Bécares, James Nazroo, Mai Stafford. The buffering effects of ethnic density on experienced racism and health. Health \& Place. 2009;15(3):700-708.

59. Klassen AC, Washington C. How does social integration influence breast cancer control among urban AfricanAmerican women? Results from a crosssectional survey. BMC Women's Health. 2008;8(4).

60. Allen JD, Stoddard AM, Sorensen G. Do Social Network Characteristics Predict Mammography Screening Practices? Health Education \& Behavior. 2008;35(6):763-776.

61. Warner ET, Gomez SL. Impact of Neighborhood Racial Composition and Metropolitan Residential Segregation on Disparities in Breast Cancer Stage at Diagnosis and Survival Between Black and White Women in California. Journal of Community Health.

2010;35:398-408.

62. Consedine N, Magai C, Krivoshekova Y, Ryzewicz L, Neugut A. Fear, anxiety, worry, and breast cancer screening behavior: A critical review. Cancer Epidemiology, Biomarkers \& Prevention. 2004;13:501-510.

63. Magai C, Consedine N, Conway F, Neugut A, Culver C. Diversity Matters: Unique populations of women and breat cancer screening. Cancer. 2004;100(11):2300-2307.

64. Taplin SH, Yabroff KR, Zapka J. A Multilevel Research Perspective on Cancer Care Delivery: The Example of Follow-Up 
to An Abnormal Mammogram. Cancer Epidemiology, Biomarkers \& Prevention. 2012;21(10):1709-1715.

65. Battaglia TA, Roloff K, Posner MA, Freund KM. Improving follow-up to abnormal breast cancer screening in an urban population. A patient navigation intervention. Cancer. 2007;109(2):359367.

66. Percac-Lima S, Cronin PR, Ryan DP, Chabner BA, Daly EA, Kimball AB. Patient Navigation Based on Predictive Modeling Decreases No-Show Rates in Cancer Care. Cancer. 2015;121(4).

67. Percac-Lima S, Ashburner JM, Bond B, Oo SA, Atlas SJ. Decreasing disparities in breast cancer screening in refugee women using culturally tailored patient navigation. Journal of General Internal Medicine. 2013;28(11):14631468.

68. Wells KJ, Battaglia TA, Dudley DJ, Garcia R, Greene A, Calhoun E, et al. Patient Navigation: State of the Art, or Is It Science? Cancer. 2008;113(8):1999-2010.

69. Paskett ED, Harrop PJ, Wells KJ. Patient Navigation: An Update on the State of the Science. A Cancer Journal for Clinicians. 2011;61(4):237-249.

70. Gabitova G, Burke NJ. Improving healthcare empowerment through breast cancer patient navigation: a mixed methods evaluation in a safety-net setting. BMC Health Services Research. 2014;14.

71. Korber SF, Padula C, Gray J, Powell M. A breast navigator program: barriers, enhancers, and nursing interventions. Oncology Nursing Forum. 2011;38(1):44-50.

72. Pedersen AE, Hack TF, McClement SE, Taylor-Brown J. An exploration of the patient navigator role: perspectives of younger women with breast cancer. Oncology Nursing Forum.
2014;41(1):77-88.

73. Gotlib Conn L, Hammond Mobilio M, Rotstein OD, Blacker S. Cancer patient experience with navigation service in an urban hospital setting: A qualitative study. European Journal of Cancer Care. 2014;24(1):1-9.

74. Campbell C, Craig J. Implementing and measuring the impact of patient navigation at a comprehensive community cancer center. Oncology Nursing Forum. 2010;37:61-68.

75. Dohan D, Schrag D. Using navigators to improve care of underserved patients: Current practices and approaches. Cancer. 2005;104(4):848-855.

76. Peek ME, Han JH. Disparities in Screening Mammography: Current Status, Interventions, and Implications. Journal of General Internal Medicine. 2004;19:184194.

77. Phillips CE, Rothstein JD, Beaver K, Sherman BJ, Freund KM, Battaglia TA. Patient navigation to increase mammography screening among inner city women. Journal of General Internal Medicine. 2011;26(2):123-129.

78. Robie L, Alexandru D, Bota DA. The use of patient navigators to improve cancer care for Hispanic patients. Clinical Medicine Insights: Oncology. 2011;5:1-7.

79. Balleyguier C, Ayadi S, Van Nguyen K, Vanel D, Dromain C, Sigal R. BIRADS classification in mammography. European Journal of Radiology. 2007;61(2):192-194.

80. US Department of Health \& Human Services. The HHS poverty guidelines for the remainder of 2010. US Department of Health \& Human Services, Washington, DC: 2010. Accessed on: Available at: http://aspe.hhs.gov/poverty/10poverty.sht $\mathrm{ml}$. 
81. Sampson R, Wilson WJ. Toward a theory of race, crime, and urban inequality. In: Hagan J, Ruth P, editors. Crime and Inequality. Stanford, CA: Stanford University Press; 1995. p. 37-56.

82. Sampson R, Raudenbush S, Earls F. Neighborhoods and violent crime: A multilevel study of collective efficacy. Science. 1997;277(15):918-924.

83. Skrondal A, Rabe-Hesketh S. Latent variable modelling: A survey. Scandinavian Journal of Statistics. 2007;34:712-745.

84. Schootman M, Jeff DB, Gillanders WE, Yan Y, Jenkins B, Aft R. Geographic clustering of adequate diagnostic followup after abnormal screening results for breast cancer among low-income women in Missouri. Ann Epidemiol. 2007 17(9):704-712.

85. Nancy Tian, J Gaines Wilson, F Benjamin Zhan. Spatial association of racial/ethnic disparities between late-stage diagnosis and mortality for female breast cancer: where to intervene? Int J Health Geogr. 2011;10:1-9.

86. Russell E, Kramer MR, Cooper HLF, Thompson WW, Arrio KRJ. Residential Racial Composition, Spatial Access to Care, and Breast Cancer Mortality among Women in Georgia. Journal of Urban Health. 2011;88(6):11171129.

87. Christopher M. Masi, Louise C. Hawkley, Z. Harry Piotrowski, Kate E. Pickett. Neighborhood economic disadvantage, violent crime, group density, and pregnancy outcomes in a diverse, urban population. Social Science \& Medicine. 2007;65(12): 2440- 2457.

88. Kate E. Pickett, James W. Collins Jr, Christopher M. Masi, Wilkinson RG. The effects of racial density and income incongruity on pregnancy outcomes. Social Science \& Medicine.
2005;60(10):2229-2238.

89. Massey D, Eggers M. The ecology of inequality: Minorities and the concentration of poverty, 1970-1980. American Journal of Sociology. 1990;95(5):1153-1188.

90. Ruby Mendenhall, Stefanie DeLuca, Greg Duncan. Neighborhood resources, racial segregation, and economic mobility: Results from the Gautreaux program Social Science Research. 2006;35(4):892-923.

91. US Department of Health \& Human Services. What are Federally qualified health centers (FQHCs)? US Department of Health \& Human Services, Washington, DC: 2015. Accessed on: Available at: http://www.hrsa.gov/healthit/toolbox/Rura lHealthITtoolbox/Introduction/qualified.ht $\mathrm{ml}$. 